\title{
Влияние легирования слоев брэгговских отражателей на электрические свойства InGaAs/GaAs метаморфных фотопреобразователей
}

\author{
(C) В.М. Емельянов, Н.А. Калюжный, С.А. Минтаиров, М.В. Нахимович, Р.А. Салий, М.З. Шварц
}

Физико-технический институт им. А.Ф. Иофрфе Российской академии наук, 194021 Санкт-Петербург, Россия

E-mail: vm.emelyanov@mail.ioffe.ru

Поступила в Редакцию 27 ноября 2019 г.

В окончательной редакции 5 декабря 2019 г.

Принята к публикации 5 декабря 2019 г.

Исследованы вольт-амперные характеристики $\mathrm{In}_{x} \mathrm{Ga}_{1-x} \mathrm{As} / \mathrm{GaAs}$ метаморфных фотопреобразователей со встроенными $n$-InGaAs/InAlAs брэгговскими отражателями с содержанием индия (In) $x=0.025-0.24$. Проведены измерения последовательного сопротивления гетероструктур в диапазоне от 90 до $400 \mathrm{~K}$. Установлено, что резкое увеличение сопротивления легированных кремнием отражателей с ростом доли индия вызвано слабой активацией донорной примеси в слоях InAlAs- $n: \mathrm{Si}$. Вследствие этого в последних образуются энергетические барьеры для основных носителей заряда высотой $0.32-0.36$ эВ, которые имеют значительную ширину. Для подавления обнаруженного эффекта разработана технология легирования $n$-InGaAs/InAlAs брэгговских отражателей теллуром (Тe), которая позволила снизить последовательное сопротивление на 5 порядков. Это позволило сохранить фактор заполнения вольт-амперной характеристики на уровне выше $80 \%$ вплоть до плотностей тока $2 \mathrm{~A} / \mathrm{cm}^{2}$. Достигнутые при этом значения квантовой эффективности фотоответа фотопреобразователей выше 85\% свидетельствуют о подавлении характерных для этого типа примеси эффектов „памяти“ и сегрегации теллура.

Ключевые слова: фотоэлектрический преобразователь, брэгговский отражатель, InGaAs, InAlAs, легирование, резистивные потери, гетерограница.

DOI: $10.21883 /$ FTP.2020.04.49148.9321

\section{1. Введение}

Повышение эффективности прямого фотоэлектрического преобразования излучения оптического диапазона в электроэнергию требует создания структур с $p-n$-переходом на основе полупроводниковых материалов с шириной запрещенной зоны $\sim 1$ эВ. Такие структуры оказываются востребованы как в роли субэлементов для многопереходных фотопреобразователей (ФП) солнечного излучения [1-4], так и для приемников-преобразователей лучистой энергии, передаваемой посредством лазерного излучения (ЛИ) [5,6].

Одним из возможных направлений создания ФП для этих целей является технология роста $\mathrm{In}_{x} \mathrm{Ga}_{1-x} \mathrm{As} /$ GaAs метаморфных гетероструктур с долей индия $x=0.17-0.24$. На сегодняшний день кпд таких ФП превысил рубежный показатель в 50\% при преобразовании лазерного излучения с длиной волны 1064 нм [7].

Дальнейшее повышение эффективности требует тщательной оптимизации как электрических, так и оптических параметров гетероструктур. Также актуальной является задача повышения радиационной стойкости ФП, используемых в солнечных батареях космических аппаратов или в оптоэлектронных системах в зонах действия ионизирующего излучения [2-4,810]. Применение брэгговских отражателей (БО) является известным подходом по улучшению поглощения излучения за счет двукратного его прохождения че- рез структуру ФП [11,12]. Это позволяет уменьшать толщину фотоактивных слоев с сохранением приемлемых значений для коэффициента собирания фотогенерированных носителей заряда в структуре при радиационном облучении $[13,14]$. Однако в статье [15] было показано, что встраивание InGaAs/AlGaAs БО в гетероструктуры метаморфных InGaAs/GaAs ФП с долей индия более $6 \%$ приводит к существенному увеличению последовательного сопротивления, что значительно снижает кпд ФП при преобразовании сконцентрированного солнечного или мощного лазерного излучений.

В данной работе исследуются механизмы резистивных потерь в InGaAs/GaAs ФП со встроенными БО, а также влияние типа мелкой примеси на величину последовательного сопротивления структуры.

\section{2. Экспериментальные гетероструктуры}

\section{1. Легированные кремнием брэгговские отражатели}

Брэгговские отражатели, легированные кремнием в качестве мелкого донора, исследовались в составе структур ФП (рис. 1, $a$ ) и отдельно (рис. 1,b). Все гетероструктуры были выращены методом металлоорганической газофазной эпитаксии (МОГФЭ) в реакторе 

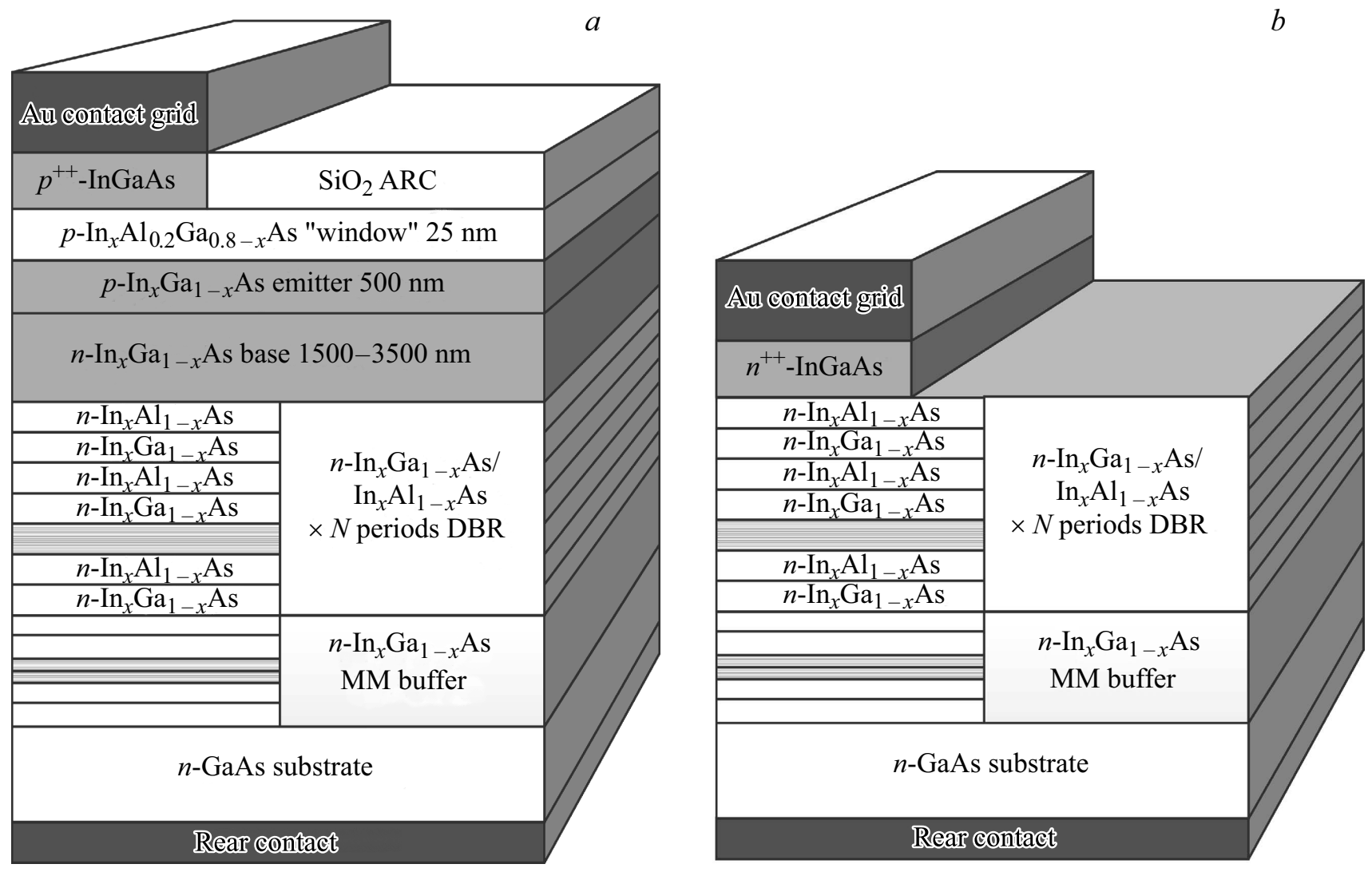

Рис. 1. ФП со встроенными БО (a) и специально изготовленные структуры с БО $(b)$.

лабораторного типа при пониженном давлении. Рост проводился на подложках $n$-GaAs. Применялась технология формирования ступенчатого метаморфного буфера, служащего для перехода к $\operatorname{In}_{x} \mathrm{Ga}_{1-x} \mathrm{As}$ слоям активной области заданного состава $x$ и предельно низкой концентрации прорастающих из метаморфного буфера дислокаций [16,17].

При росте гетероструктур в качестве источников III группы использовались металлоорганические соединения: триметилгаллий (TMGa), триметилалюминий (TMAl), триметилиндий (TMIn). Арсин $\left(\mathrm{AsH}_{3}\right)$ использовался в качестве источника мышьяка. Температура роста структур на метаморфном буфере $973 \mathrm{~K}$. Для легирования слоев в составе ФП примесью $p$-типа служил диэтилцинк (DEZn), а для создания всех слоев $n$-типа проводимости применялся моносилан $\left(\mathrm{SiH}_{4}\right)$ (5\%-я смесь силана с водородом).

Число периодов БО для ФП с долей индия 2.5-21\% составляло 20. Для образцов с содержанием индия 23-24\% число периодов БО было меньше: 4, 8 или 12. Перечень структур с БО и их основные параметры представлены в таблице.

Расчетное легирование слоев БО составляло $2 \cdot 10^{19} \mathrm{~cm}^{-3}$. Однако достижение такой высокой концентрации примеси с помощью кремния на практике является невыполнимой задачей. Основное преимущество использования $\mathrm{Si}$ в качестве традиционной донорной примеси в МОГФЭ - это отсутствие так называемого „эффекта памяти“, заключающегося в адсорбции атомов на внутренних поверхностях реакционной камеры и последующей их десорбции и переноса в растущий слой. Однако для кремния существует проблема активации примеси при высоких $\left(n>0.5-1 \cdot 10^{19} \mathrm{~cm}^{-3}\right)$ уровнях легирования. В МОГФЭ атом кремния обычно встраивается в подрешетку элементов III группы $\mathrm{A}^{\mathrm{III}} \mathrm{B}^{\mathrm{V}}$ полупроводника, давая дополнительный электрон. Но, являясь атомом IV группы, может рассматриваться и как амфотерная примесь, имея возможность встраивания в подрешетку элементов V группы и давая дырку в качестве носителя. На практике это выражается в том, что при достижении высокого уровня легирования $\mathrm{A}^{\mathrm{III}} \mathrm{B}^{\mathrm{V}}$ слоя концентрация активных электронов прекращает увеличиваться при увеличении мольной фракции $\mathrm{SiH}_{4}$ в газовой фазе. Этот недостаток $\mathrm{SiH}_{4}$ особенно сильно может сказываться на легировании широкозонных, алюминийсодержащих, полупроводников.

\section{2. Легированные теллуром брэгговские отражатели}

Структуры, предназначенные для исследования влияния теллура в качестве мелкого донора, также приведены в таблице. Они включали пять образцов отражателей (см. рис. 1,b) и один ФП со встроенным 
Параметры специально изготовленных структур с БО и гетероструктур ФП со встроенными БО

\begin{tabular}{|c|c|c|c|c|c|c|}
\hline $\begin{array}{c}\text { Легирование } \\
n \text {-InGaAs/InAlAs-слоев БО }\end{array}$ & $\begin{array}{c}\text { Тип } \\
\text { структуры }\end{array}$ & $\begin{array}{c}\text { № } \\
\text { структуры }\end{array}$ & $\begin{array}{c}\text { Содержание In } \\
\text { в фотоактивных } \\
\text { слоях и БО, \% }\end{array}$ & $\begin{array}{c}\text { Число } \\
\text { периодов БО }\end{array}$ & $\begin{array}{c}\text { Длина волны } \\
\text { настройки БО, нм }\end{array}$ & $\begin{array}{c}\text { Число } \\
\text { образцов } \\
\text { данного вида }\end{array}$ \\
\hline \multirow{3}{*}{$\mathrm{Si}$} & ФП с БО & $\begin{array}{l}1 \\
2 \\
3 \\
4\end{array}$ & $\begin{array}{l}2.5 \\
3 \\
6 \\
21\end{array}$ & $\begin{array}{l}20 \\
20 \\
20 \\
20\end{array}$ & $\begin{array}{r}840 \\
840 \\
840 \\
1064\end{array}$ & $\begin{array}{l}1 \\
2 \\
2 \\
1\end{array}$ \\
\hline & БО & 5 & 23 & 12 & 1064 & 1 \\
\hline & ФП с БО & $\begin{array}{l}6 \\
7 \\
8\end{array}$ & $\begin{array}{l}24 \\
24 \\
24\end{array}$ & $\begin{array}{r}4 \\
8 \\
12\end{array}$ & $\begin{array}{l}1064 \\
1064 \\
1064\end{array}$ & $\begin{array}{l}1 \\
1 \\
1\end{array}$ \\
\hline \multirow{3}{*}{$\mathrm{Te}$} & БО & 9 & 17 & 12 & 1064 & 1 \\
\hline & ФП и БО & 10 & 17 & 12 & 1064 & 1 \\
\hline & БО & $\begin{array}{l}11 \\
12\end{array}$ & $\begin{array}{l}23 \\
23\end{array}$ & $\begin{array}{r}6 \\
12\end{array}$ & $\begin{array}{l}1064 \\
1064\end{array}$ & $\begin{array}{l}2 \\
2\end{array}$ \\
\hline
\end{tabular}

БО (см. рис. 1, $a$ ). В качестве источника легирующей примеси, теллура, использовался диэтилтеллур (DETe). Слои, легированные теллуром, выращивались при температуре $873 \mathrm{~K}$.

Для достижения высокой $\left(2 \cdot 10^{19} \mathrm{~cm}^{-3}\right)$ концентрации донорной примеси в МОГФЭ можно использовать атомы элементов VI группы, которые, в отличие от кремния, стабильно замешают атомы подрешетки элементов $\mathrm{V}$ группы $\mathrm{A}^{\mathrm{III}} \mathrm{B}^{\mathrm{V}}$ полупроводника, создавая дополнительный свободный электрон. Известным из литературы недостатком источников примесей VI группы, в частности диэтилтеллура (DETe), является заметный „эффект памяти“ [18]. Кроме того, радиус атома Те достаточно большой по сравнению с As, поэтому возможно частичное „выдавливание“ легирующей примеси и сегрегация теллура по мере роста эпитаксиального слоя.

Ранее с помощью DETe была достигнута высокая (вплоть до $2.5 \cdot 10^{19} \mathrm{~cm}^{-3}$ ) концентрация активных доноров при легировании GaAs эпитаксиальных слоев в процессе МОГФЭ, что позволило продемонстрировать GaAs- $n:$ Te контактные системы с рекордно низким сопротивлением [19]. При выращивании легированных теллуром БО требовалось не только продемонстрировать высокую концентрацию активной донорной примеси в его слоях, что должно выражаться в низком сопротивлении структуры БО, но и подавить „эффект памяти“ и процесс сегрегации Те во время роста базовой области. Для этого, в частности, после завершения роста БО с теллуром, структура отжигалась в водороде, а температура в реакторе поднималась до $973 \mathrm{~K}$, после чего область базы ФП выращивалась с использованием $\mathrm{SiH}_{4}$ в качестве легирующей примеси. Свидетельством подавления процесса сегрегации и нивелирования „эффекта памяти“ должна быть высокая квантовая эффективность ФП.

\section{3. Результаты и их анализ}

Для исследования фотоэлектрических характеристик экспериментальных образцов структур с БО и ФП использовалось следующее оборудование:

- спектральный комплекс [20] для регистрации спектральных зависимостей внешнего квантового выхода фотоответа ФП и спектров отражения ФП и БО;

- импульсный имитатор солнечного излучения с системой измерения для записи нагрузочных (при освещении) вольт-амперных характеристик (BAX) ФП и темновых (без освещения) ВАХ структур с БО [21]. При исследовании температурных зависимостей фотоэлектрических параметров образцы помещались в оптический криостат, обеспечивающий контролируемое изменение температуры образца от 90 до $400 \mathrm{~K}$.

\section{1. Характеристики легированных кремнием брэгговских отражателей}

ВАХ БО, легированного кремнием, формировалась методом вычитания значений напряжений для точек с равными токами, получаемыми из вольтамперных характеристик для ФП с БО и для контрольного ФП близкой гетероструктурой, но без отражателя. Также регистрировались ВАХ специально созданных структур БО (см. рис. $1, b)$.

Анализ полученных характеристик показал следующее:

- форма ВАХ БО не зависит от величины фототока ФП;

- зависимость тока от приложенного напряжения остается практически линейной в диапазоне смещений 


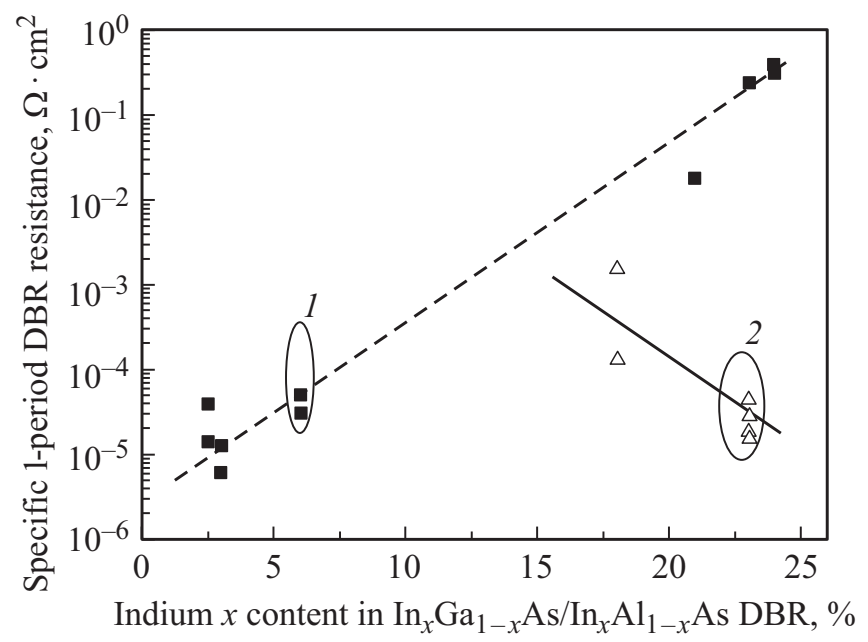

Рис. 2. Эквивалентное сопротивление одного периода БО $R_{\mathrm{DBR}}$ при температуре $298 \mathrm{~K}$ в зависимости от доли индия в метаморфной гетероструктуре. Легирующая примесь БО: 1 - кремний, 2 - теллур.

от 0 до 3 В и может быть описана при помощи „эквивалентного сопротивления БО“;

- величина эквивалентного сопротивления БО пропорциональна числу периодов отражателя.

Результаты оценок последовательного сопротивления в пересчете на один период БО (рис. 2) свидетельствуют об экспоненциальном характере нарастания сопротивления при увеличении доли индия в слоях InGaAs/InAlAs БO.
Заметные резистивные потери в $\mathrm{A}^{\mathrm{III}} \mathrm{B}^{\mathrm{V}}$ ФП могут быть вызваны энергетическими барьерами треугольной формы вблизи гетерограниц, которые возникают изза разрывов валентной зоны или зоны проводимости [22-24]. В данном случае доминирующим механизмом протекания тока через барьер обычно является термоэлектронная эмиссия Шоттки:

$$
\begin{gathered}
J(V, T) \sim T^{2} \exp \left(-\frac{q \varphi_{0}}{k T}\right) \exp \left(\frac{\alpha \sqrt{V}}{T}\right), \\
\alpha=\sqrt{\frac{q}{4 \pi \varepsilon d}},
\end{gathered}
$$

или механизм Пула-Френкеля:

$$
J(V, T) \sim V \exp \left(-\frac{q \varphi_{0}}{k T}\right) \exp \left(\frac{2 \alpha \sqrt{V}}{T}\right),
$$

где $\varphi_{0}, d-$ эффективная высота и ширина барьера, $\varepsilon-$ диэлектрическая проницаемость, $V$ - напряжение, $k-$ постоянная Больцмана, $T$ - абсолютная температура.

На рис. 3 приведена ВАХ БО (структура 5), состоящего из 12 периодов пар слоев $\mathrm{In}_{0.23} \mathrm{Ga}_{0.77} \mathrm{As} / \mathrm{In}_{0.23} \mathrm{Al}_{0.77} \mathrm{As}$, легированных кремнием. Диапазон измерения ВАХ по напряжению был ограничен возникающим пробоем структуры. Также представлены зависимости тока $J$ и эквивалентной проводимости $J / V$ от квадратного корня напряжения. Из представленных графиков видно, что законы (1) и (2) не отражают наблюдаемые электрические характеристики отражателя. Для дальнейшего исследования механизмов протекания тока через БО были
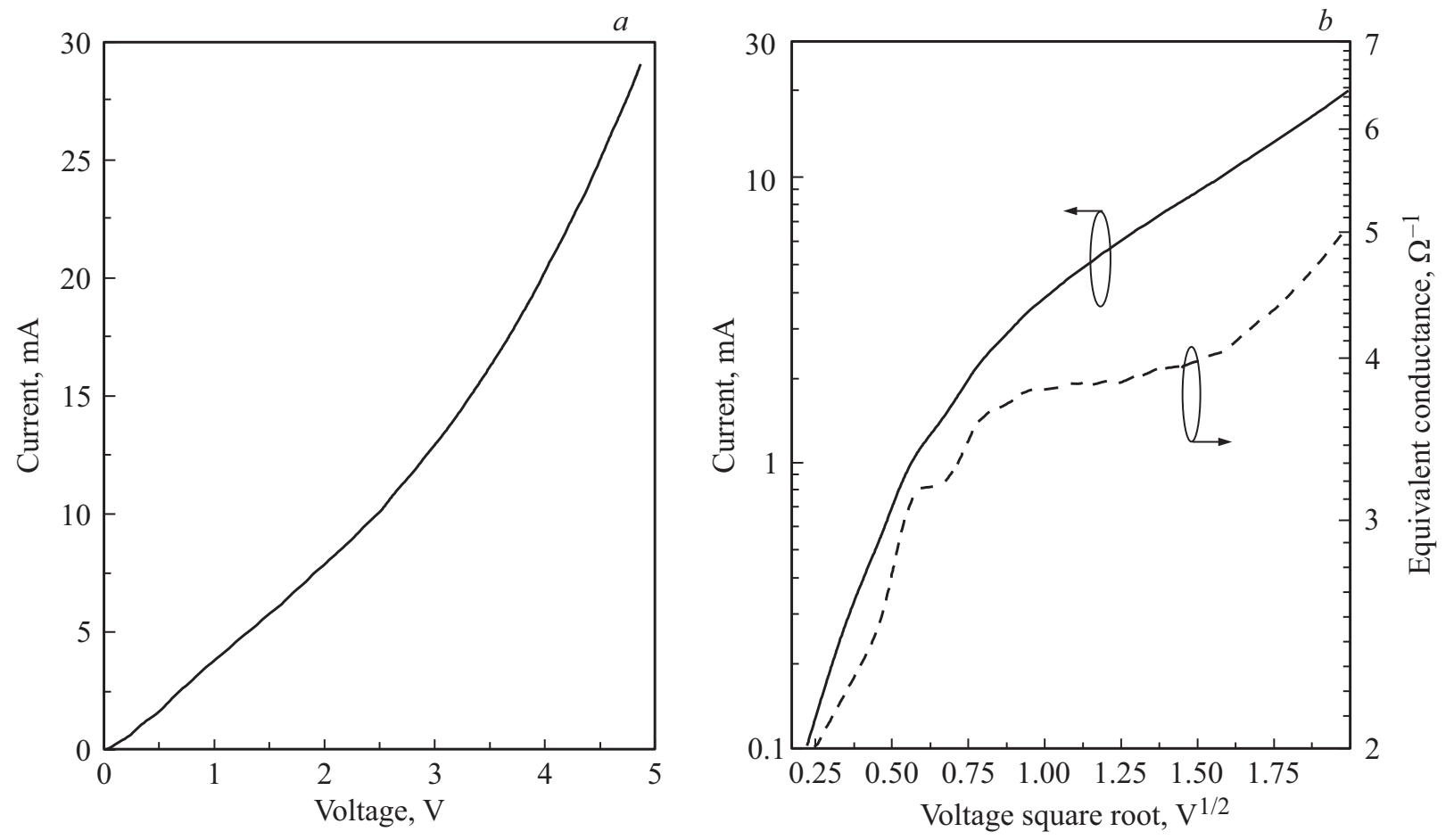

Рис. 3. ВАХ БО, легированного кремнием (структура 5, см. таблицу). 

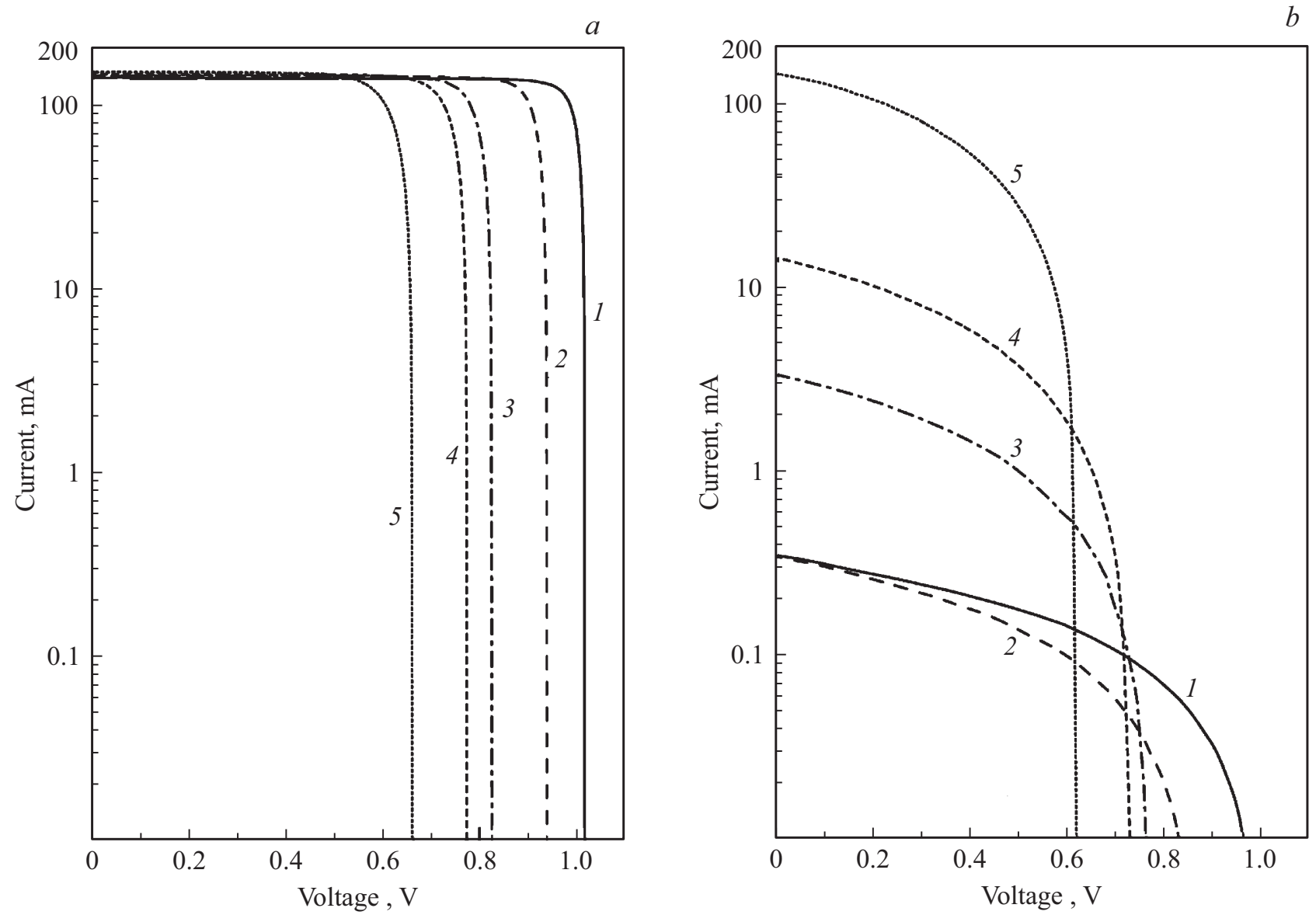

Рис. 4. $\mathrm{BAX} \mathrm{In}_{0.24} \mathrm{Ga}_{0.76} \mathrm{As} / \mathrm{GaAs}$ ФП без БО $(a)$ и со встроенным 12-периодным БО (структура 8, см. таблицу), легированным кремнием $(b)$. Абсолютная температура, К: $1-123,2-183,3-263,4-298,5-373$.

измерены ВАХ ФП (структуры 6-8) при повышенных и пониженных температурах.

\section{2. Температурные измерения проводимости брэгговских отражателей}

Измерения нагрузочных ВАХ ФП проводились в диапазоне температур от 98 до $373 \mathrm{~K}$ с шагом $10-15^{\circ}$. Величина фототока во всех случаях стабилизировалась на уровне 150 мА при $298 \mathrm{~K}$. Вольт-амперные характеристики легированных кремнием БО при пониженных и повышенных температурах выделялись из ВАХ ФП тем же способом, что и при комнатных температурах (см. разд. 3.1).

Зависимости тока от напряжения для $\mathrm{In}_{0.24} \mathrm{Ga}_{0.76} \mathrm{As} /$ GaAs ФП со встроенным БО и без него для нескольких температур изображены на рис. 4. Видно, что при повышенной температуре $373 \mathrm{~K}$ БО не ограничивает ток ФП, однако достаточно заметно влияет на величину фактора заполнения ВАХ. Снижение температуры ФП, с одной стороны, увеличивает напряжение холостого хода, а с другой - вызывает рост резистивных потерь у структуры с БО. Уже при комнатной температуре возникает ограничение тока короткого замыкания, кото- рое усиливается по мере охлаждения образца вплоть до температур от 100 до $200 \mathrm{~K}$, где наблюдается „полка“ на температурной зависимости сопротивления (рис. 5). Наклон зависимости при температуре выше $200 \mathrm{~K}$ пропорционален $\exp (-0.32$ эВ $/ k T)$.

Экспериментально измеренная зависимость сопротивления БО от температуры может быть удовлетворительно аппроксимирована формулой:

$$
R_{\mathrm{DBR}}(T)=\rho_{0} N_{\mathrm{DBR}} d_{\mathrm{AlInAs}}, \quad \rho_{0}^{-1}=\left(\rho_{1}^{-1}+\rho_{2}^{-1}\right)^{-1},
$$

где

$$
\rho_{2} \propto \exp (-0.32 \text { эВ } / k T)
$$

или

$$
\rho_{2} \propto T^{2} \exp (-0.36 \text { эВ } / k T) .
$$

Здесь $N_{\mathrm{DBR}}$ - число периодов БО, $\rho_{0}$ - удельное сопротивление на единицу толщины слоя InAlAs, $d_{\text {InAlAs }}-$ толщина слоя InAlAs в БО. Результат аппроксимации также приведен на рис. 5. Различия при использовании формул (4) и (5) не видны в масштабе графика.

Величина разрыва зоны проводимости для гетерограницы $n$-InGaAs/InAlAs составляет $0.285-0.52$ эВ в зависимости от доли индия в полупроводниковых материалах [24-26]. Полученная с учетом этого диаграмма 


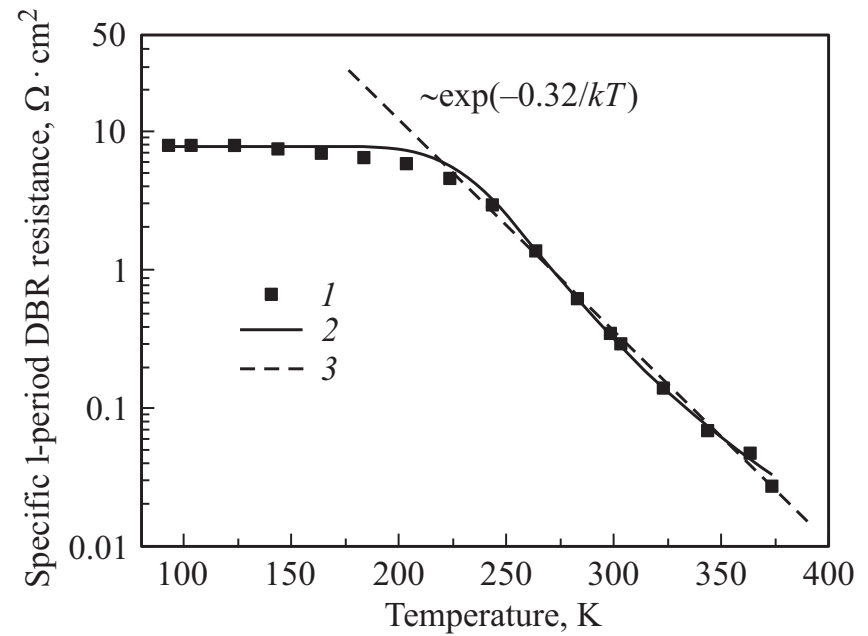

Рис. 5. Зависимость эквивалентного сопротивления одного периода БО $R_{\mathrm{DBR}}$ в метаморфной гетероструктуре с долей индия $24 \%$, легированной кремнием: $1-$ результаты измерений, 2 - аппроксимация по формулам (3) и (5), 3 - аппроксимация по формуле (4).

для последовательного сопротивления БО может быть объяснена переносом носителей заряда за счет процесса термоэлектронной эмиссии между слоями InGaAs БО через слои InAlAs, образующие достаточно широкий барьер прямоугольной формы. При заданном в технологическом процессе уровне легирования донорной примесью слоя InAlAs высота барьера в 0.32-0.36 эВ не должна достигаться, а ширина последнего должна обеспечивать его практически полную прозрачность. Широкий и высокий барьер может возникать, если вносимая в InAlAs мелкая примесь остается не активированной. При этом наличие „Полки“ для сопротивления в области низких температур определяется туннельным механизмом транспорта носителей заряда, а также утечками в структуре.

Таким образом, можно сделать вывод, что эффективность кремния как мелкой примеси для слоев InAlAs снижается с увеличением в них доли индия, что и приводит к росту последовательного сопротивления БО (см. рис. 2).

\section{3. Характеристики легированных теллуром брэгговских отражателей}

Полученные результаты исследования температурных свойств БО, легированных кремнием, позволили сделать вывод о нецелесообразности использования последнего для формирования донорного типа проводимости слоев InAlAs при доле алюминия более 6\%. По этой причине была разработана технология легирования БО теллуром и изготовлены образцы со структурами 9-12 (см. таблицу).

Для структур БО, а также ФП со встроенным БО были измерены спектральные и вольт-амперные характе- ристики. На основании ВАХ был выполнен расчет эквивалентного последовательного сопротивления периода БО, результаты которого представлены на рис. 2 в сравнении со структурами, легированными кремнием. Применение теллура в качестве мелкого донора позволяет снизить последовательное сопротивление БО примерно на $\sim 5$ порядков, что свидетельствует о высокой концентрации активной донорной примеси в слоях InAlAs- $n$ : Te. Несколько большее сопротивление для структур с долей индия 17\% является, по всей видимости, артефактом изготовления конкретных экспериментальных образцов и будет улучшено в дальнейшем.

Разработанная технология роста InGaAs/InAlAs БО, легированных теллуром, была применена при изго-

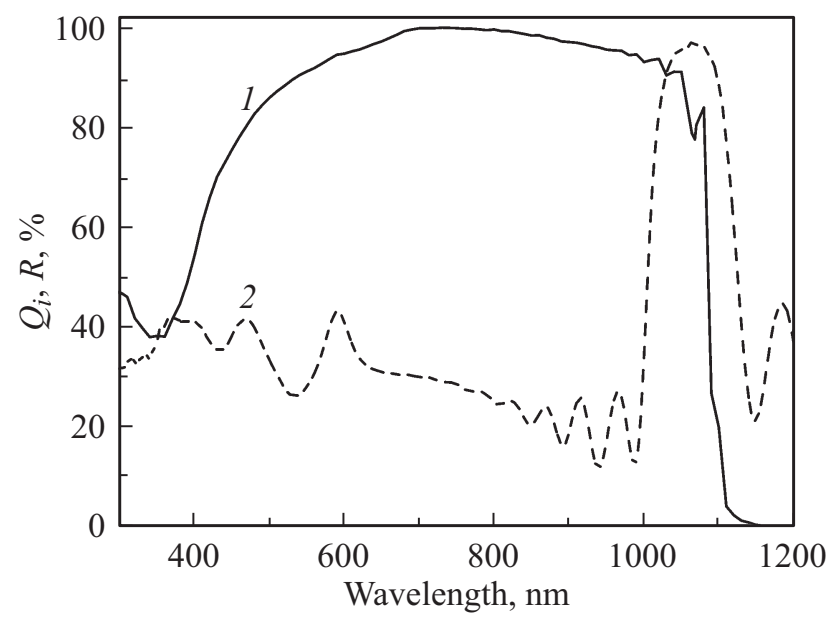

Рис. 6. Экспериментальная спектральная зависимость внутреннего квантового выхода фотоответа $Q_{i}$ для $\operatorname{In}_{0.17} \mathrm{Ga}_{0.83} \mathrm{As} /$ GaAs ФП со встроенным 12-периодным БО, легированным теллуром ( 1 , структура 10$)$, и коэффициент отражения $R$ для $\mathrm{In}_{0.17} \mathrm{Ga}_{0.83} \mathrm{As} / \mathrm{In}_{0.17} \mathrm{Al}_{0.83} \mathrm{As}$ БО (2, структура 9$)$. Номера структур соответствуют таблице.

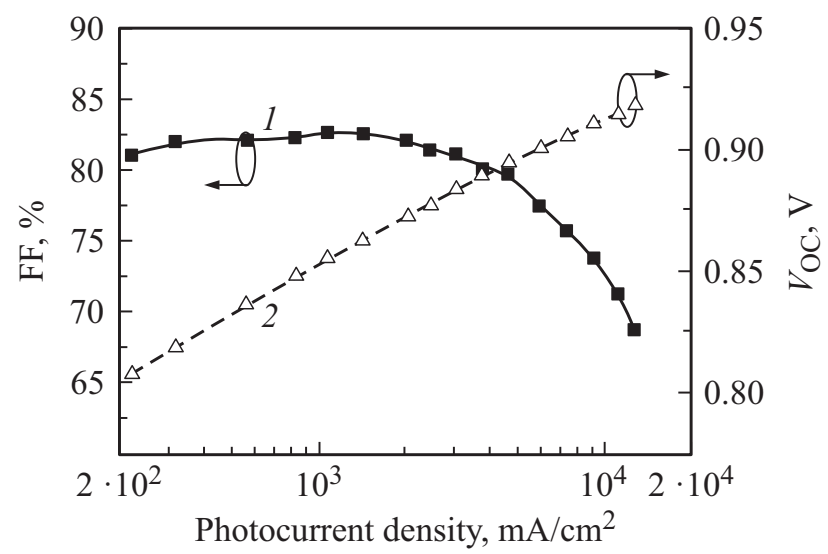

Рис. 7. Зависимости фактора заполнения $\mathrm{BAX}(1)$ и напряжения холостого хода (2) от плотности фототока для экспериментального $\mathrm{In}_{0.17} \mathrm{Ga}_{0.83} \mathrm{As} / \mathrm{GaAs}$ ФП со встроенным 12-периодным БО, легированным теллуром (структура 10 , см. таблицу). 
товлении метаморфных $\operatorname{In}_{0.17} \mathrm{Ga}_{0.83} \mathrm{As} / \mathrm{GaAs-cтруктур} \mathrm{со}$ встроенным БО для ФП. Спектральная зависимость внутреннего квантового выхода, а также зависимости фактора заполнения BAX и напряжения холостого хода от фототока представлены на рис. 6 и 7 соответственно. Использование теллура для легировании БО позволяет сохранить диффузионные длины носителей заряда, достаточные для получения высоких значений квантовой эффективности, а также рабочего напряжения элемента [7]. Таким образом, влияние „эффекта памяти“ и сегрегации Те на оптические характеристики метаморфных ФП можно считать нивелированными. При этом сниженное последовательное сопротивление ФП обеспечивает сохранение фактора заполнения ВАХ выше $80 \%$ вплоть до плотностей тока $2 \mathrm{~A} / \mathrm{cm}^{2}$. Последний параметр может быть дополнительно улучшен при оптимизации технологического процесса (см. рис. 2).

\section{4. Заключение}

Результаты исследования вольт-амперных характеристик БО на основе метаморфных гетероструктур $\mathrm{In}_{x} \mathrm{Ga}_{1-x} \mathrm{As} / \mathrm{In}_{x} \mathrm{Al}_{1-x} \mathrm{As} \quad(x=0.17-0.24)$, выращенных на подложках $\mathrm{GaAs}$, показали, что наблюдаемый рост последовательного сопротивления при легировании БО кремнием обусловлен снижением активации растворенной примеси. Данный эффект становится более заметным с ростом содержания индия в твердом растворе. Это приводит к тому, что в слоях InAlAs образуются энергетические барьеры высотой $0.32-0.36$ эВ и значительной ширины, ток термоэлектронной эмиссии через которые приводит к заметным резистивным потерям.

Разработанная технология легирования БО теллуром обеспечила снижение эффективной величины барьера на гетерогранице $n$-InGaAs/ $n$-InAlAs, обусловленной различием энергии электронного сродства для двух материалов, до приемлемых значений. Это позволило уменьшить последовательное сопротивление БО на 5 порядков по сравнению с отражателями, легированными кремнием. Также продемонстрированы высокие (более 85\%) значения внутреннего квантового выхода фотоответа ФП со встроенным БО.

Полученные результаты подтверждают перспективность создания высокоэффективных ФП на основе метаморфных $\mathrm{In}_{x} \mathrm{Ga}_{1-x} \mathrm{As} / \mathrm{GaAs}$ гетероструктур со встроенными БО и оптимизированным оптическим дизайном. Соответствующие фотоэлектрические ячейки могут эффективно использоваться и в многопереходных солнечных элементах, и в ФП мощного лазерного излучения для повышения их радиационной стойкости.

\section{Благодарности}

Исследование выполнено при финансовой поддержке РФФИ в рамках научного проекта № 16-29-03216.

\section{Конфликт интересов}

Авторы заявляют об отсутствии конфликта интересов.

\section{Список литературы}

[1] F. Dimroth, T.N.D. Tibbits, M. Niemeyer, F. Predan, P. Beutell, C. Karcher, E. Oliva, G. Siefer, D. Lackner, P. Fuß-Kailuweit, A.W. Bett, R. Krause, C. Drazek, E. Guiot, J. Wasselin, A. Tauzin, T. Signamarcheix. IEEE J. Photovolt., 6, 343 (2016).

[2] N. Miller, P. Patel, C. Struempel, C. Kerestes, D. Aiken, P. Sharps. AIP Conf. Proc., 1616, 50 (2014).

[3] P. Sharps, D. Aiken, B. Cho, S. Cruz, D. Derkacs, N. Fatemi, A. Haas, C. Kerestes, N. Miller, B. Pantha, P. Patel, M. Stan, A. Stavrides, J. Steinfeldt, C. Struempel, S. Whipple. E3S Web Conf., 16, 03002 (2017).

[4] P.T. Chiu, D.C Law, R.L. Woo, S.B. Singer, D. Bhusari, W.D. Hong, A. Zakaria, J. Boisvert, S. Mesropian, R.R. King, N.H. Karam. Proc. 40th IEEE PVSC, 11 (2014).

[5] N.A. Kalyuzhnyy, V.M. Emelyanov, S.A. Mintairov, M.Z. Shvarts. AIP Conf. Proc., 2012, 110002 (2018).

[6] Y. Kim, H.B. Shin, W.H. Lee, S.H. Jung, C.Z. Kim, H. Kim, Y.T. Lee, H.K. Kang. Solar Energy Mater. \& Solar Cells, 200, 109984 (2019).

[7] N.A. Kalyuzhnyy, V.M. Emelyanov, V.V. Evstropov, S.A. Mintairov, M.A. Mintairov, M.V. Nahimovich, R.A. Salii, M.Z. Shvarts. AIP Conf. Proc., 2149, 050006 (2019).

[8] S.R. Messenger. Electronics Science and Technology Division Seminar (15 March, 2001) p. 201.

[9] M. Meusel, C. Baur, W. Guter, M. Hermle, D. Frank, A. Bett, T. Bergunde, R. Dietrich, R. Kern, W. Köstler, M. Nell, W. Zimmermann. Proc. 20th EUPVSEC, 20 (2005).

[10] A.S. Vlasov, V.M. Emelyanov, E.S. Aronova, O.I. Chosta, N.A. Kalyuznyy, S.A. Mintairov, M.Z. Shvarts, A.N. Trufanov. Proc. 29th EUPVSEC, 347 (2010).

[11] V.M. Lantratov, I.V. Kochnev, M.Z. Shvarts. Proc. 27th SOTAPOCS Electrochem. Soc., 21, 125 (1997).

[12] X. Duan, Y. Huang, Y. Shang, J. Wang, X. Ren. Optics Lett., 39 (8), 2447 (2014).

[13] M.Z. Shvarts, O.I. Chosta, I.V. Kochnev, V.M. Lantratov, V.M. Andreev. Solar Energy Mater. \& Solar Cells, 68, 105 (2001).

[14] В.М. Емельянов, Н.А. Калюжный, С.А. Минтаиров, М.3. Шварц, В.М. Лантратов. ФТП, 44 (12), 1649 (2010).

[15] V.M. Emelyanov, M.A. Mintairov, N.A. Kalyuzhnyy, S.A. Mintairov, M.Z. Shvarts. AIP Conf. Proc., 2012, 090003 (2018).

[16] N.A. Kalyuzhnyy, S.A. Mintairov, A.M. Nadtochiy, V.N. Nevedomskiy, D.V. Rybalchenko, M.Z. Shvarts. Electron. Lett., 53 (3), 173 (2017).

[17] Д.В. Рыбальченко, С.А. Минтаиров, Р.А. Салий, Н.Х. Тимошина, М.З. Шварц, Н.А. Калюжный. ФТП, 51 (1), 94 (2017).

[18] Y.M. Houng, T.S. Low. J. Cryst. Growth, $77(1-3), 272$ (1986).

[19] А.В. Неженцев, В.И. Егоркин, В.Е. Земляков, В.И. Гармаш, Н.А. Калюжный, С.А. Минтаиров. Микроэлектроника, 47 (6), 431 (2018). 
[20] M.Z. Shvarts, A.E. Chalov, E.A. Ionova, V.R. Larionov, D.A. Malevskiy, V.D. Rumyantsev, S.S. Titkov. Proc. 20th EUPVSEC, 278 (2005).

[21] В.Р. Ларионов, Д.А Малевский, П.В Покровский, В.Д. Румянцев. ЖТФ, 85 (6), 104 (2015).

[22] R. Hoheisel, A.W. Bett. IEEE J. Photovolt., 2 (3) 398 (2012).

[23] A.S. Gudovskikh, K. Zelentsov, N. Kalyuzhnyy, V. Evstropov, V.M. Lantratov, S. Mintairov. J. Phys. D: Appl. Phys., 45, 495305 (2012).

[24] M.Z. Shvarts, A.S. Gudovskikh, N.A. Kalyuzhnyy, S.A. Mintairov, A.A. Soluyanov, N.Kh. Timoshina, A. Luque. AIP Conf. Proc., 1616, 29 (2014).

[25] S.C. Jain, D.J. Roulston. Solid State Electron, 34 (5), 453 (1991).

[26] E. Wolak, J.C. Harmand, T. Matsuno, K. Inoue, T. Narusawa. Appl. Phys. Lett., 59(1), 111 (1991).

[27] M.S. Hybertsen. Appl. Phys. Lett., 58 (16), 1759 (1991).

Редактор Г.А. Оганесян

\title{
Effects of Bragg reflector layers' doping in the electrical characteristics of InGaAs/GaAs metamorphic photovoltaic converters
}

\author{
V.M. Emelyanov, N.A. Kalyuzhnyy, S.A. Mintairov, \\ M.V. Nakhimovich, R.A. Salii, M.Z. Shvarts
}

loffe Institute,

194021 St. Petersburg, Russia

\begin{abstract}
The current-voltage characteristics of $\mathrm{In}_{x} \mathrm{Ga}_{1-x}$ As/GaAs metamorphic photovoltaic converters with built-in $n$-InGaAs/InAlAs Bragg reflectors at In content of $x=0.025-0.24$ have been investigated. Series resistance measurements of heterostructures in the range from 90 to $400 \mathrm{~K}$ have been carried out. It was found that raising of the resistance of silicon-doped reflectors with an increase in the proportion of $\mathrm{In}$ is caused by weak activation of donors in InAlAs- $n: \mathrm{Si}$ layers. As a result, the latter form energy barriers for the main charge carriers with a height of $0.32-0.36 \mathrm{eV}$, which have a significant width. To suppress the detected effect, the technology of Te doping of $n$-InGaAs/InAlAs Bragg reflectors has been developed, which reduced the series resistance by five orders of magnitude. This allowed to keep the fill factor of the current-voltage characteristic at a level above $80 \%$ up to current densities of $2 \mathrm{~A} / \mathrm{cm}^{2}$. The achieved values of the quantum efficiency above $85 \%$ indicate the suppression of the „memory“ and segregation effects that are common to Te-doped layers.
\end{abstract}

